\title{
P-0611 - Invasive fungal rhinosinusitis in patients with diabetes
}

\section{: a case series}

\section{Raizada N, Jyotsna VP, Xess I, Thakar A, Kandasamy D, Tandon N. AlIMS, New Delhi, INDIA}

An ambispective study of invasive fungal rhinosinusitis in patients with diabetes mellitus was carried at the All India Institute of Medical Sciences, Delhi, India. A total of 22 patients were identified in a 7 year period (2008 2015). The mean age was 44.1 yrs(13.9) and 12 were male. Three patients had type 1 diabetes and rest had type 2 diabetes. The patients did not have any history of immunosuppression or malignancy.

The imaging findings were reported at baseline, 30,60, 90 and 120 days of admission (the day 30 represents imaging findings of any radiological study done between 3-6 weeks of admission. Day 60 represents study done between 6-9 weeks, day 90 represents study done at 9-12 weeks and day 120 represents after 12 weeks). Disease was staged at these intervals as sinonasal, orbital or intracranial. The progression of disease was also studied at day 30, 60 and 90 and reported as static, worse or improved. 'Static' was defined as disease which is similar to the previous imaging (for example, baseline imaging for the day 30 imaging report). 'Worse' was defined as evidence of increase in the disease with respect to the previous imaging. 'Improved' was defined as reduction of disease as compared to the previous imaging. The criteria used to assess progression were extent of disease, involvement of new areas, abscess formation and contrast enhancement. The outcome of the study was assessed as visual loss or death at end of hospital stay and as death at last follow up.

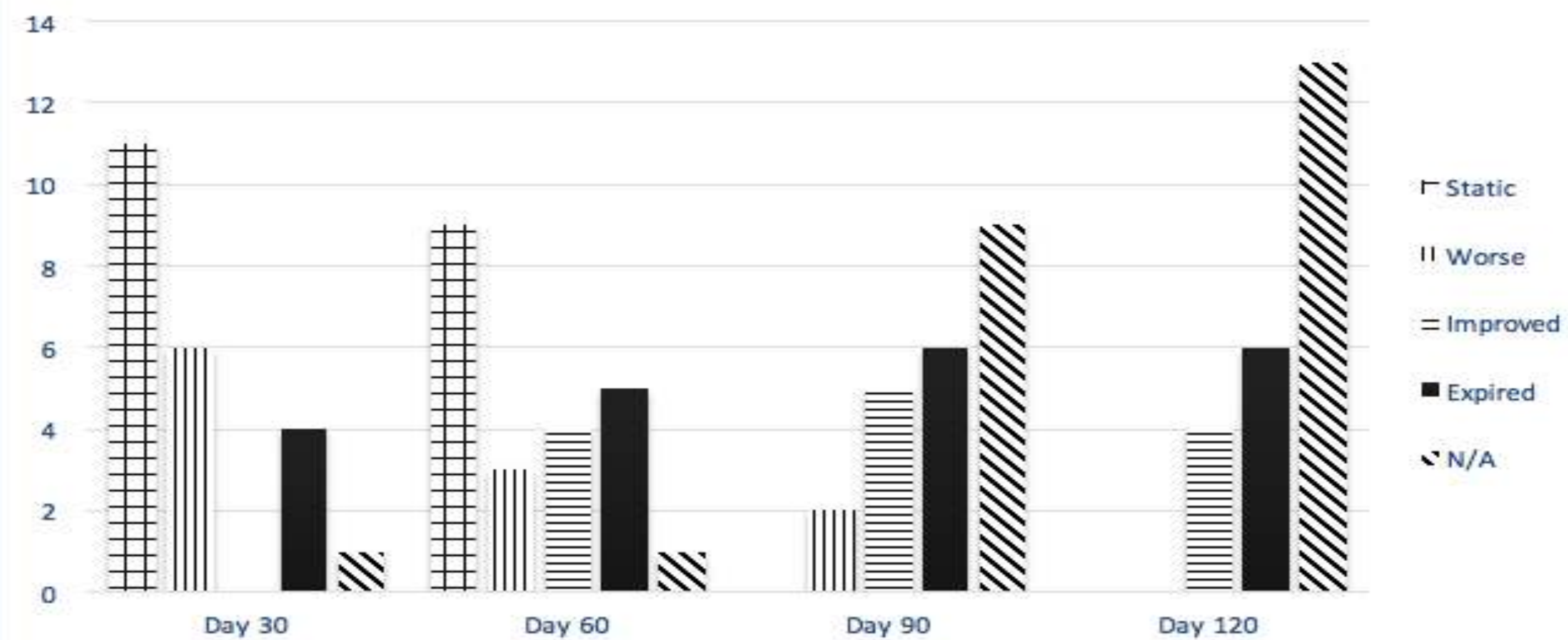

Figure 2. Radiological disease progression (N/A-Not available)

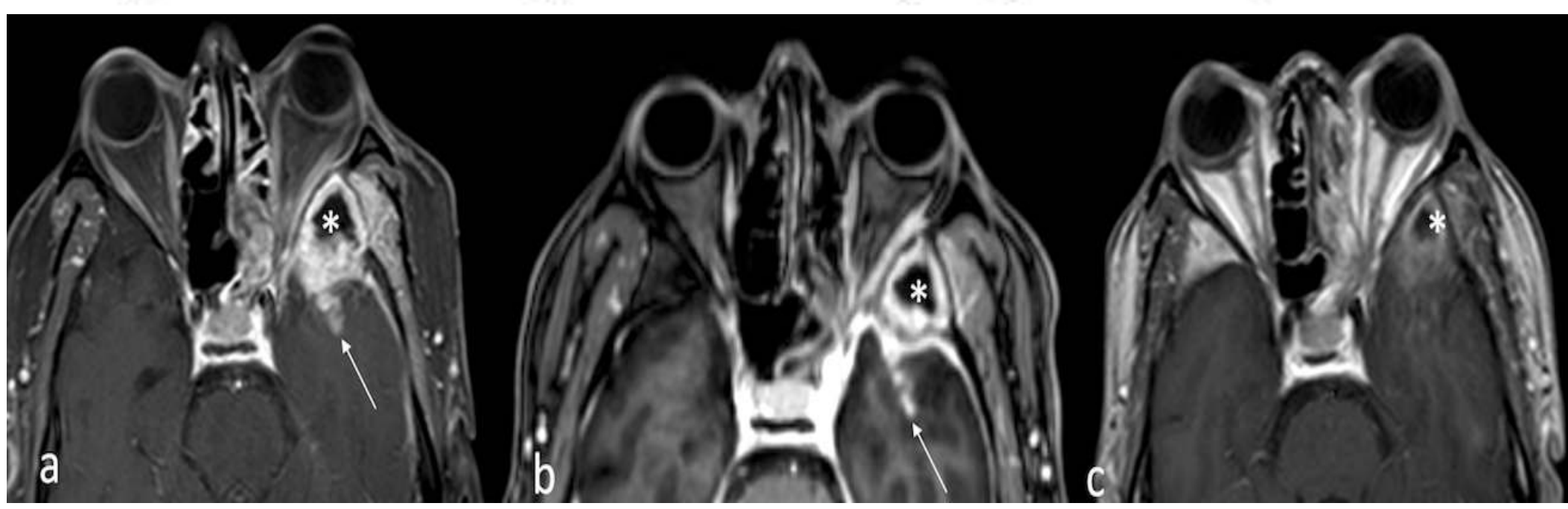

Figure I.Progressive improvement of the disease. Baseline MR TI W post gadolinium image in axial plane (a) showing osteomyelitis involving the left greater wing of sphenoid bone(asterisk) and involement of anterior part of left temporal lobe(arrow) with associated pachymeningeal thickening. The follow up scans done on day 60(b) and day 90 (c) showing significant improvement with near total disappearence of abnormalities

None of the patients showed radiological improvement at day 30 imaging including those who subsequently improved. Of the 11 patients with orbital disease, six developed intracranial extension during the hospital stay. The six deaths included all the four cases with diabetic ketoacidosis. Diabetic ketoacidosis, baseline intracranial disease Use of liposomal amphotericin B was not associated with a better survival compared to conventional amphotericin B.

\begin{tabular}{|l|l|}
\hline N & 22 \\
\hline $\begin{array}{l}\text { Diabetic } \\
\text { ketoacidosis }\end{array}$ & 5 \\
\hline $\begin{array}{l}\text { Most common } \\
\text { presenting } \\
\text { feature }\end{array}$ & $\begin{array}{l}\text { Facial } \\
\text { swelling/ } \\
\text { pain }\end{array}$ \\
\hline $\begin{array}{l}\text { Intracranial } \\
\text { disease at } \\
\text { (baseline) }\end{array}$ & 4 \\
\hline $\begin{array}{l}\text { Orbital disease at } \\
\text { baseline }\end{array}$ & $\mathbf{I}$ \\
\hline $\begin{array}{l}\text { Mucormycosis } \\
\text { Liposomal } \\
\text { amphotericin B }\end{array}$ & $\mathbf{2 I}$ \\
\hline $\begin{array}{l}\text { Deaths at end of } \\
\text { hospital stay }\end{array}$ & 4 \\
\hline $\begin{array}{l}\text { Deaths at last } \\
\text { follow up }\end{array}$ & 6 \\
\hline $\begin{array}{l}\text { Loss of vision in } \\
\text { one eye }\end{array}$ & $70 \%$ \\
\hline
\end{tabular}

